\title{
Mini-Review
}

\section{Cortical Mechanisms for Pitch Representation}

\author{
Timothy D. Griffiths $\mathbf{s}^{1,2}$ \\ ${ }^{1}$ Institute of Neuroscience, Newcastle University Medical School, Newcastle upon Tyne, NE2 4HH, United Kingdom, and ${ }^{2}$ Wellcome Trust Centre for \\ NeuroImaging, University College London, London WC1N 3BG, United Kingdom
}

Pitch is critical to the perception of music and speech and for sound-source segregation, and is one of a number of perceptual attributes that can be associated with a sound object. An understanding of the neural mechanisms for pitch perception is needed to explain important aspects of human perception, but work on neural substrates uses different techniques in different species and it is a moot point whether 'universal' pitch mechanisms might exist. In these reviews we examine critically the extent to which this might be the case.

Pitch perception requires neural mechanisms to create a representation corresponding to the percept from sensory cues in the frequency and time domains. Oxenham (2012) will consider the fundamental question of the relationship between sensory properties and perceived pitch that constrains what might be legitimately called a pitch mapping in brain experiments. Sensory cues that are necessary for pitch perception are represented in the ascending auditory pathway and cortex. We consider here the distinct but related question: what are the neural correlates of the pitch percept itself? Cortical mechanisms for pitch representation are implicated by studies at three different levels of neural organization. We take a broad perspective here that includes single-neuron recording in ferret and marmoset (Wang and Walker, 2012), local field-potential recordings from neural ensembles in humans (Kumar and Schönwiesner, 2012), measurement of the fMRI BOLD response related to neural ensemble activity in macaques and humans (Griffiths and Hall, 2012), and the modeling of interactions between neural ensembles in humans (Kumar and Schönwiesner, 2012).

Pitch mappings are first considered at the level of neurons that represent the pitch percept rather than the frequency- or time-structure of the stimulus. Such representation is arguably similar to the coding of perceived color rather than the frequency of light in certain visual neurons (Zeki, 1973). From first principles, a single pitch value might be represented by activity in single neurons that are tuned to a given pitch value or as an ensemble property of a group of less well tuned neurons. Neurons in marmoset auditory cortex (Bendor and Wang, 2005) can show tuning to the pitch of a complex stimulus that is similar to that of a pure tone consistent with representing perceived pitch. Those neurons are precisely tuned. Neurons in ferret auditory cortex (Walker et al., 2011) can represent pitch information in parallel with information about spatial location and timbre (defined as sound percep-

Received April 4, 2012; revised July 18, 2012; accepted July 23, 2012.

Correspondence should be addressed to Timothy D.Griffiths at the above address. E-mail:t.d.griffiths@ncl.ac.uk. DOI:10.1523/JNEUROSCI.1661-12.2012

Copyright $\odot 2012$ the authors $\quad 0270-6474 / 12 / 3213333-02 \$ 15.00 / 0$ tual attributes distinct from pitch and location). Neurometric analyses suggest that, based on ferret neurons such as these, a given pitch would need to be coded by multiple neurons (Bizley et al., 2010), in contrast to the highly tuned marmoset pitch neurons. Wang and Walker (2012) consider the issue of neuron versus ensemble codes. Although species differences might be relevant, a possible solution is the existence of distinct neurons that abstract pitch (create a neural correlate of pitch from sensory information) as opposed to neurons that simply represent pitch information after such abstraction.

The second possible level of pitch representation is a pitch area: a specialized cortical region in which pitch is represented, like one of the proposed color centers in the visual cortex of macaque and humans (see Tootell et al., 2003, for one viewpoint). Such an area might contain single neurons that are capable of encoding single pitch values or less selective neurons that encode pitch as an ensemble property. The marmoset neurons above were all demonstrated in one area, while the ferret neurons showing less precise responses to pitch were found in multiple cortical areas. In humans we generally only have access to data based on responses from neural ensembles using fMRI, MEG, EEG, and local field potentials from invasive recordings in neurosurgical subjects. Early human fMRI studies (Patterson et al., 2002; Penagos et al., 2004) focused on single pitch types, while recent work (Barker et al., 2012) emphasizes that a pitch area should have similar responses to the pitch percept regardless of the stimulus with which the pitch happens to be associated. Human fMRI studies suggest localized pitch responses in auditory cortex, but ongoing debate concerns the precise anatomical location of these areas and the relationship between mechanisms for pitch and timbre analysis in auditory cortex. Griffiths and Hall (2012) will discuss these issues. Local field potentials recorded from human auditory cortex (Schönwiesner and Zatorre, 2008; Griffiths et al., 2010), to be discussed by Kumar and Schönwiesner (2012), also demonstrate activity in auditory cortex that is a correlate of the pitch percept in neuronal ensembles.

A third possible level of pitch representation in the cortex is at the level of a constructive system for pitch: a system based on effective connectivity between areas at different levels in a cortical hierarchy. Kumar and Schönwiesner (2012) will present evidence for such organization in human auditory cortex based on modeling of depth-electrode data (Kumar et al., 2011; Kumar and Schönwiesner, 2012).

Work addressing all three levels of organization is now establishing specialized neural mechanisms for pitch analysis in the cortex. The extent to which these might prove to be universal will continue to be debated. 


\section{References}

Barker D, Plack CJ, Hall DA (2012) Reexamining the evidence for a pitchsensitive region: a human fMRI study using iterated ripple noise. Cereb Cortex 22:745-753. CrossRef Medline

Bendor D, Wang X (2005) The neuronal representation of pitch in primate auditory cortex. Nature 436:1161-1165. CrossRef Medline

Bizley JK, Walker KM, King AJ, Schnupp JW (2010) Neural ensemble codes for stimulus periodicity in auditory cortex. J Neurosci 30:5078-5091. CrossRef Medline

Griffiths TD, Hall DA (2012) Mapping pitch representation in neural ensembles with fMRI. J Neurosci 32:13343-13347. CrossRef

Kumar S, Schönwiesner M (2012) Mapping human pitch representation in a distributed system using depth-electrode recordings and modeling. J Neurosci 32:13343-13347.CrossRef

Kumar S, Sedley W, Nourski KV, Kawasaki H, Oya H, Patterson RD, Howard MA 3rd, Friston KJ, Griffiths TD (2011) Predictive coding and pitch processing in the auditory cortex. J Cogn Neurosci 23:3084-3094. CrossRef Medline

Oxenham AJ (2012) Pitch perception. J Neurosci 32:13335-13338.CrossRef Patterson RD, Uppenkamp S, Johnsrude IS, Griffiths TD (2002) The pro- cessing of temporal pitch and melody information in auditory cortex. Neuron 36:767-776. CrossRef Medline

Penagos H, Melcher JR, Oxenham AJ (2004) A neural representation of pitch salience in nonprimary human auditory cortex revealed with functional magnetic resonance imaging. J Neurosci 24:6810-6815. CrossRef Medline

Schönwiesner M, Zatorre RJ (2008) Depth electrode recordings show double dissociation between pitch processing in lateral Heschl's gyrus and sound onset processing in medial Heschl's gyrus. Exp Brain Res 187:97105. CrossRef Medline

Tootell RBH, Tsao D, Vanduffel W (2003) Neuroimaging weighs in: humans meet macaques in "primate" visual cortex. J Neurosci 23:39813989. Medline

Walker KM, Bizley JK, King AJ, Schnupp JW (2011) Multiplexed and robust representations of sound features in auditory cortex. J Neurosci 31: 14565-14576. CrossRef Medline

Wang X, Walker KM (2012) Neural mechanisms for the abstraction and use of pitch information in auditory cortex J Neurosci 32:13339-13342. CrossRef

Zeki SM (1973) Colour coding in rhesus monkey prestriate cortex. Brain Res 53:422-427. CrossRef Medline 